\title{
Design \& Development of High Gain Antenna Arrays for CDMA 450
}

\author{
Azhari Asrokin, Anas Abas \\ Next Generation Access Division \\ Telekom Research \& Development Sdn Bhd \\ Cyberjaya, Selangor, Malaysia \\ \{azhari.asrokin\}\{anas\}@ tmrnd.com.my
}

\author{
Rizal Helmy Basri, Norman Jamlus \\ Enabling Science Division \\ Telekom Research \& Development Sdn Bhd \\ Cyberjaya, Selangor, Malaysia \\ \{helmy\}\{norman\}@ tmrnd.com.my
}

\begin{abstract}
This paper brief on the research and development work on high gain CDMA450 antenna done in TM R\&D. Basic PCB antenna dipoles were arranged in arrays to form a more directional antenna to increase gain while at the same time reduce back lobes which helps to decrease the effect of signal looping between donor and subscriber antenna in repeater system. The designed antenna achieved $15 \mathrm{~dB}$ gain and VSWR below 1.5 .
\end{abstract}

Keywords-dipole; CDMA; array; repeater; donor antenna; dipole

\section{INTRODUCTION}

CDMA frequency band was utilized by Telekom Malaysia (TM) since the analogue era of ATUR until the era of digital by using the CDMA2000 1x system along with CDMA2000 EVDO [1]. The CDMA network provided by TM is a compliment to the TM's core business which is in fixed line by providing services to inaccessible area (not commercially recommended to lay telephone line) or places which are highly targeted for cable theft which mainly situated in rural areas [2]. To support the government initiative to increase broadband penetration in Malaysia, TM with its existing infrastructure, do provide data services at certain rural areas (especially near the TM exchange building) which is called the Streamyx Wireless [2]. To reduce the cost of building up new base station and the base station operation while increasing the profit by providing better coverage service to the users, the use of repeaters is needed [3].

A repeater system consists of 2 types of antennas which are the donor antenna and the subscriber or serving antenna [4]. The donor antenna should have a high gain so that radio frequency (RF) signal from the closest base station can be received by the repeater. The subscriber antenna should have foot print pattern according to the needs of the intended coverage area either it should be small or big (in terms of $3 \mathrm{~dB}$ horizontal beamwidth).

CDMA technology is being utilized by TM as it offers benefits unlike any other technology. Its main advantages is the operating frequency of the system which is at $450 \mathrm{MHz}$ and $800 \mathrm{MHz}$. In terms of coverage areas, CDMA at $450 \mathrm{MHz}$ can offer the widest coverage area compared to GSM, UMTS and any higher frequency systems [5]. This advantage is a selling point to deploy low cost communication infra especially in rural areas. Other advantages and disadvantages of using CDMA 450 can be found in [5].

The material for the antenna is printed circuit board (PCB) using Flame Retardant-4 (FR-4) as the substrate with thickness of $1.6 \mathrm{~mm}, \mathrm{FR}-4$ permittivity $\left(\varepsilon_{\mathrm{r}}\right) 4.7$, tangent loss $(\tan \delta) 0.019$ and copper thickness $0.035 \mathrm{~mm}$. The metal plate used as the base plate or grounding is made of aluminium with thickness of $2 \mathrm{~mm}$.

\section{METHODOLOGY}

The design of this antenna array is a continuation of previous work as stated in [6]. The methodology of achieving the desired results is the same with [6] or otherwise will be stated in the following paragraph.

\section{A. Single Element Design}

The antenna element design is based on half wavelength dipole antenna [7]. The antenna is designed on FR-4 PCB board which the width, $\mathrm{W}$ of the antenna changes the input impedance of the antenna which is around $0.125 \lambda$. The length, $\mathrm{L}$ is around $0.5 \lambda$. The height of the antenna, $\mathrm{H}$ is around $0.25 \lambda$. Since this paper objective is to achieve a better result in term of gain, the required antenna separation is much more that $\mathrm{L}$, the previous design of using a bended dipole antenna [6] can be replaced with a simpler dipole design as shown below.

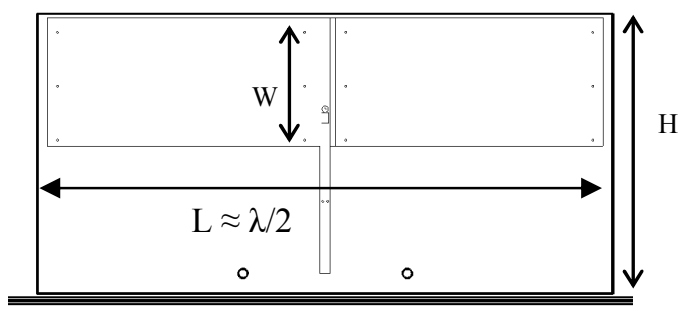

Figure 1. Dimension for dipole antenna

\section{B. Antenna Array}

The antenna elements are aligned in $4 \times 4$ arrays. The distance between the elements in $\mathrm{X}$ axis is fixed to $\approx \lambda$ while in the $\mathrm{Z}$ axis is fixed to $\approx \lambda / 2$. The overall size for the base plate is $\approx 4 \lambda \times 3 \lambda$ as illustrated in figure 2 . 


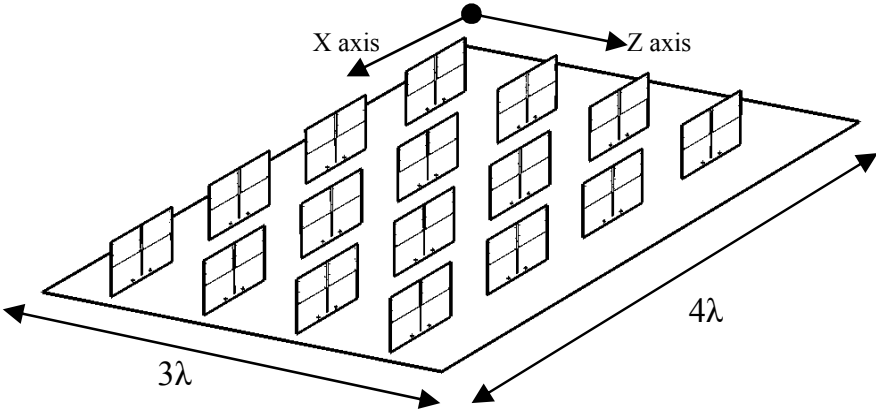

Figure 2. Dimension of the designed $4 \times 4$ antenna arrays.

The antenna arrays are being fed with horizontal and vertical corporate feed network as shown in figure 3. The 1-to4 power divider modules can be an equal power divider or an un-equal power divider depending on the requirement of the application. For this paper presentation, the equal power division was used.

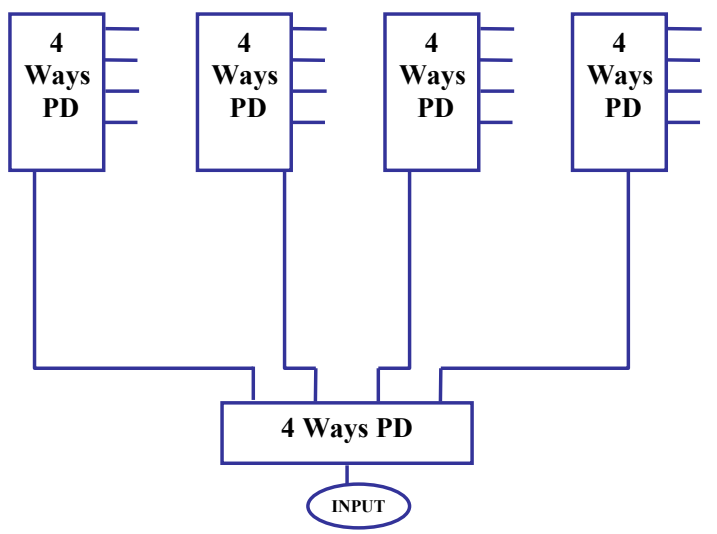

Figure 3. Feed network configuration of the $4 \times 4$ antenna arrays.

\section{Power Divider}

The power divider modules are consisting of 3 individual Wilkinson power divider integrated into one module. The Wilkinson power divider was designed based on design rules in [8]. For the whole feed network, the design required 15 power divider which after it was integrated, it only becomes 5 modules. The feed network is represented in CST Design Studio as shown in figure 4. No cable was defined in the Design Studio to simplify the design work as there is no phase difference to each output ports to the antenna (same cable length is used).

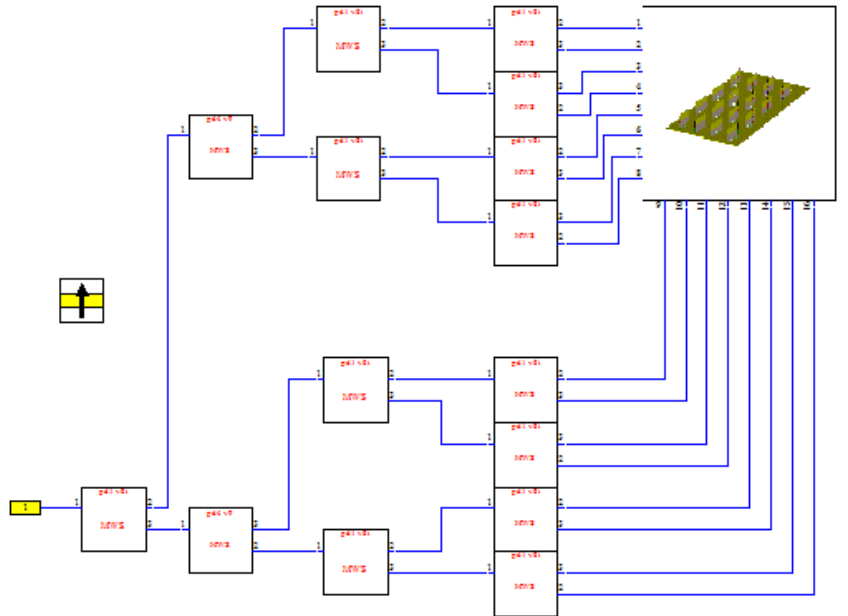

Figure 4. Integrated feed network of the antenna array in CST Design Studio.

\section{RESULTS AND DISCUSSIONS}

\section{A. Single Antenna}

The VSWR for the each dipole antenna was measured and shown in figure 5. The antenna achieved VSWR below 2 from 450 to $470 \mathrm{MHz}$. It shows that the antennas are working at its optimal level.

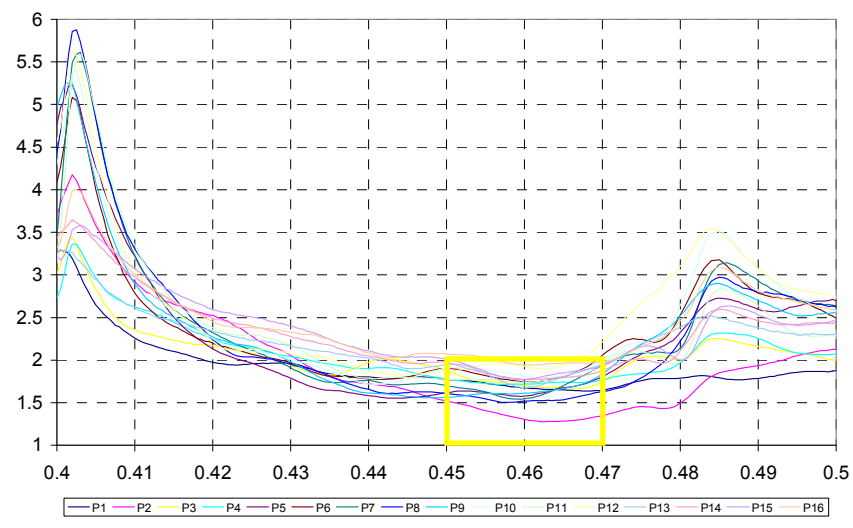

Figure 5. Measured VSWR for single element bended dipole antenna.

\section{B. Antenna Array}

The summary of the simulated and the measured results is as shown in table 1. In overall, it shows a good correlation between the simulated and the measured results except for the VSWR. Its difference might be caused by the many small parts in the antenna integration which is not represented during simulation process which if it is modelled in CST, it will increase the mesh cells number thus increasing the simulation time. The antenna array was modelled in CST as simple as possible as shown previously in figure 2 . 
TABLE I.

RESUlt SuMMARY OF THE High GAIN ANTENNA.

\begin{tabular}{|c|c|c|}
\hline & Simulated & Measured \\
\hline Frequency Range & $450-470 \mathrm{MHz}$ & $450-470 \mathrm{MHz}$ \\
\hline VSWR & $\leq 2.8$ & $\leq 1.4$ \\
\hline Gain & $16.19 \mathrm{~dB}$ & $15 \mathrm{~dB}$ \\
\hline Polarization & Vertical & Vertical \\
\hline $\begin{array}{c}\text { Horizontal } \\
\text { Beam Width }\end{array}$ & $31.9^{\circ}$ & $35^{\circ}$ \\
\hline $\begin{array}{c}\text { Vertical } \\
\text { Beam Width }\end{array}$ & $17.3^{\circ}$ & $18^{\circ}$ \\
\hline Front-to-back ratio & $20 \mathrm{~dB}$ & $27.8 \mathrm{~dB}$ \\
\hline
\end{tabular}

The VSWR achieved for the whole antenna system is as shown in figure 6 . It shows that the antenna almost achieve required VSWR specification of below 1.5.

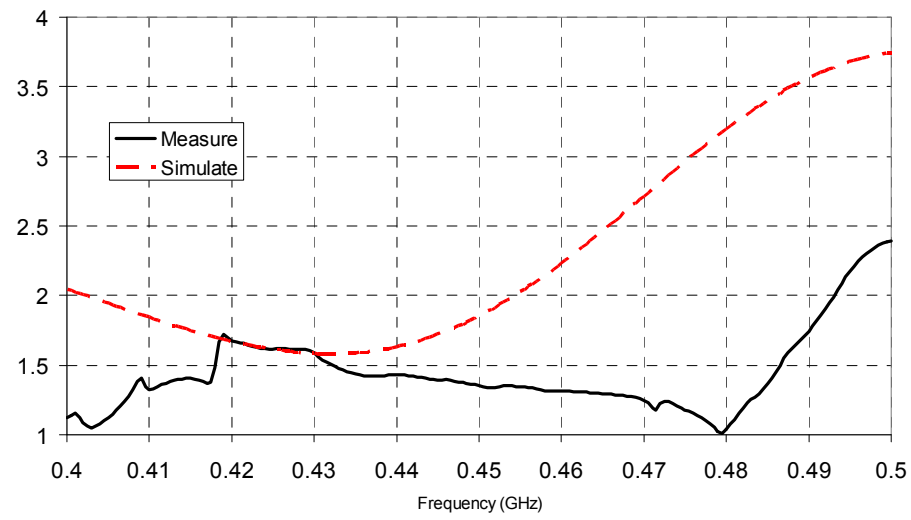

Figure 6. VSWR of the antenna array system.

Figure 7 and 8 shows the radiation pattern for the donor antenna. It can be observed that the simulated and measured horizontal radiation pattern is almost correlates to each other. The back lobe of the simulated result is much higher than the measured result due to modeling limits in CST. The horizontal beamwidth for simulated result is around 31 degree while for measured result is around 35 degree.

It also happens to the vertical pattern in figure 8 , where the back lobe of the simulated result is much higher than the measured result. The simulated result also shows that the vertical pattern is skewed around 5 degrees to the left side of the polar plot. It might have been caused by the unsymmetrical output power produced by the power divider module. The vertical beamwidth for simulated result is around 17 degree while for measured result is around 18 degree.

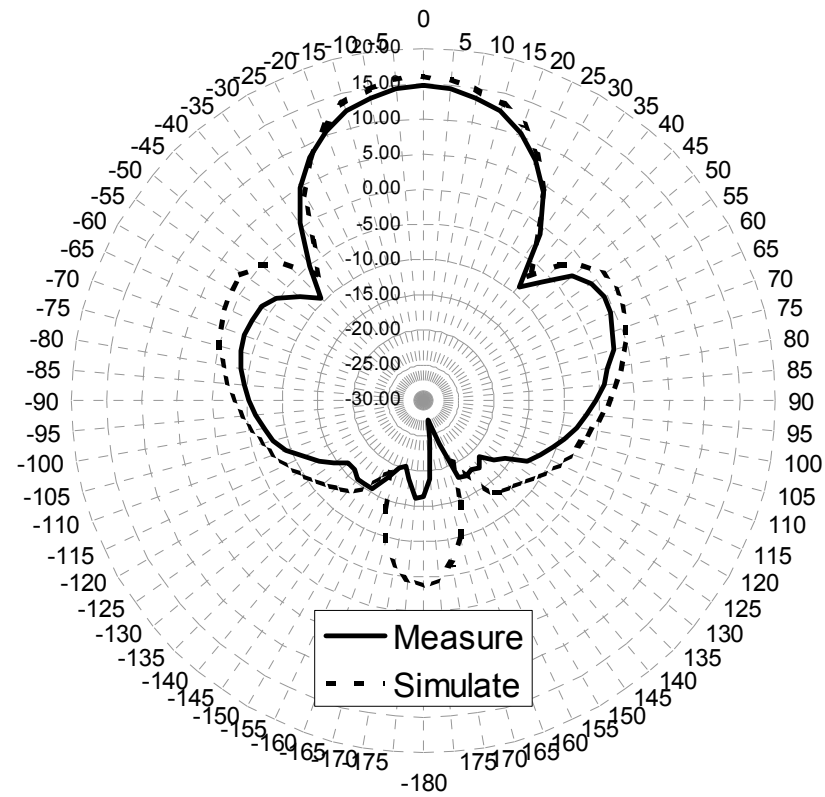

Figure 7. Horizontal radiation pattern for the complete antenna array.

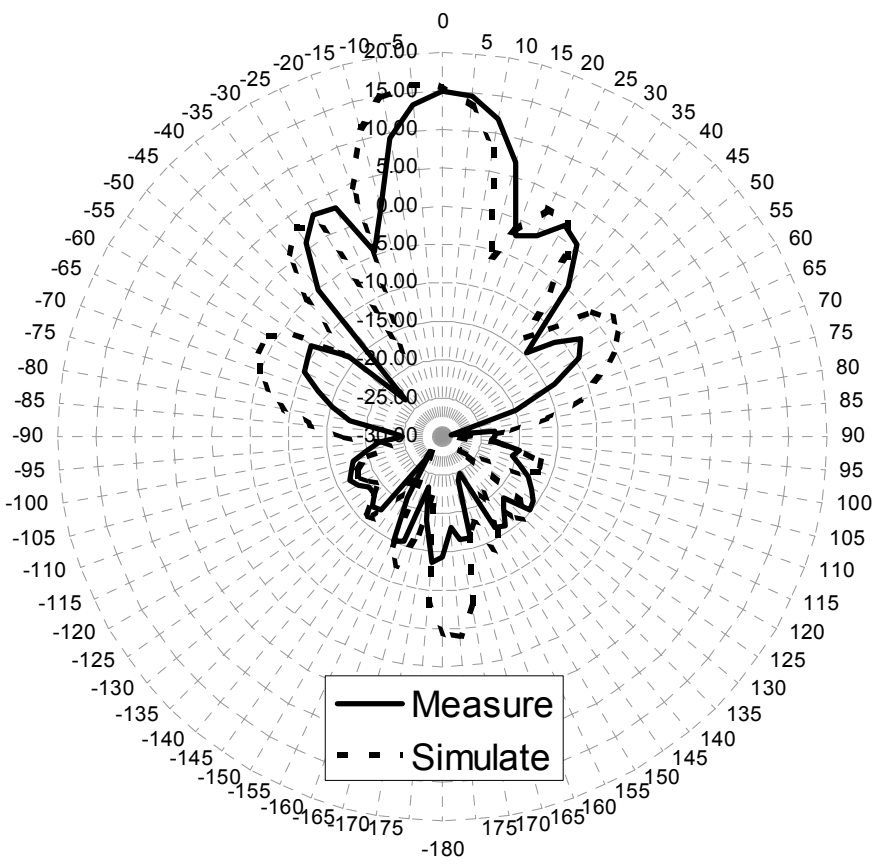

Figure 8. Vertical radiation pattern for the complete antenna array.

In figure 9, it can be observed that along the operating frequency of CDMA450 $(450 \mathrm{MHz}-470 \mathrm{MHz})$, the antenna gain is around $15 \mathrm{~dB}$. The measured gain is $1.5 \mathrm{~dB}$ lower than the simulated result might be due to inconsistent individual antenna's performance which will affect the overall performance. 


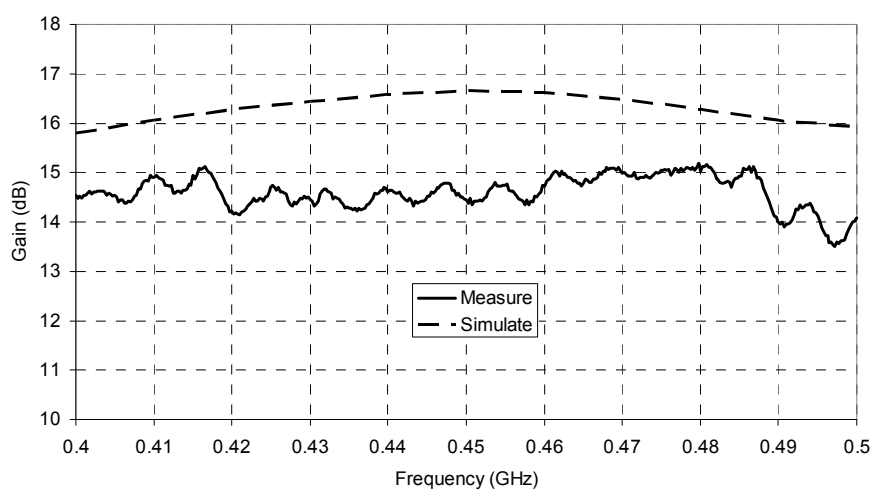

Figure 9. Gain versus frequency.

\section{CONCLUSION}

An antenna array which operates at $450 \mathrm{MHz}$ was successfully designed and developed in TM R\&D. Several lesson learned which involved in designing the power dividers and feed network integration has been identified which are:

a. For designing 2-way Wilkinson power divider, the isolation between the two output ports is important to decrease looping between the two output ports.

b. Separation between antenna elements is important to achieve the desired performance. Cable length and cable assembly needs to be precise to ensure there are no phase differences coming out from each antenna.

c. The process for optimizing the results for all cases should be handled by the Optimizer feature which can be found in Transient Solver option in CST. With the help of Distributing Computing feature, it helps to reduce the simulation time for all design especially the Wilkinson power divider.

The antenna is expected to be tested on a field trial site soon to examine its capability in the real situation. The antenna performance is actually limited to the size of the array which increases the difficulty level to install the antenna to a telecommunication tower. The antenna size also influence its wind loading capacity which a tropical country like Malaysia is well known for its windy and rainy weather throughout the year, thus affecting the antenna's boom strength to support the antenna from such big forces from all possible direction of the wind at the top of the telecommunication tower. Therefore, a robust design of the antenna boom is required so that the antenna can withstand high speed wind and rain in Malaysia.

\section{REFERENCES}

[1] http://www.cdg.org

[2] http://www.tm.com.my

[3] http://www.qualcomm.com/common/documents/white_papers/Network PlanningwithRepeaters.pdf

[4] Niemelä, J. , Lähdekorpi, P. , Borkowski, J. , Lempiäinen, J., "Assessment of Repeaters for WCDMA UL and DL Performance in Capacity-Limited Environment," $14^{\text {th }}$ IST Mobile \& Wireless Communication Summit. Dresden, June 2005.

[5] Sergiu Nedevschi, Sonesh Surana, Bowei Du, Rabin Patra, Eric Brewer, Victor Stan, Zapp Telemobil, "Potential of CDMA450 for Rural Network Connectivity," IEEE Communications Magazine, Vol 45 Issue 1, January 2007, pg $128-135$.

[6] A. Asrokin, A. Abas, R. H. Basri, N. Jamlus, "Simulation on the 4 x 5 Antenna Arrays at $450 \mathrm{MHz}$," 2010 IEEE Asia-Pacific Conference on Applied Electromagnetics (APACE 2010), N. Sembilan, Malaysia, 9-11 November 2010.

[7] C. A. Balanis, "Antenna Theory: Analysis and Design," $3^{\text {rd }}$ Edition. New Jersey, 2005.

[8] D. M. Pozar, "Microwave Engineering," $2^{\text {nd }}$ Edition. USA, 1998. 